\title{
LA JUSTICIA RESTAURATIVA DESDE LA PRÁCTICA PENITENCIARIA
}

\author{
Guadalupe Rivera González \\ Subdirectora General de Medio Abierto y Penas y Medidas Alternativas. \\ Secretaría General de Instituciones Penitenciarias.
}

SUMARIO: 1. Introducción: Justicia Restaurativa en entorno europeo. - 2. Justicia restaurativa en España. - 3. Justicia restaurativa en instituciones penitenciarias. - 4. Cambio de paradigma/proyecto global. - 5. Taller de diálogos restaurativos. - 6. Encuentros Restaurativos Penitenciarios. - 7. Implementación. - 8. Futuro de la Justicia Restaurativa. - 9. Bibliografía 10. - Documentos.

\section{Introducción: Justicia restaurativa en entorno europeo}

En el momento actual y en el entorno europeo, uno de los principales referentes que marcan la práctica de la justicia restaurativa, es la reciente Recomendación 2018 del Comité de Ministros del Consejo de Europa referente a la Justicia Restaurativa en asuntos penales. En ella, se anima a los Estados Miembros al uso de programas restaurativos y a la inclusión de los mismos dentro de los sistemas de justicia criminal. Igualmente propone una definición por la que se entiende la justicia restaurativa como cualquier «proceso que permite a aquellos afectados por el delito y aquellos responsables del daño, si aceptan voluntariamente, a participar activamente en la resolución de los asuntos derivados del delito, a través de la ayuda de un tercero entrenado e imparcial denominado facilitador

Ya en el año 2015, el Foro Europeo de Justicia Restaurativa, EEFRJ, publicó la guía Orientación para el desarrollo de la justicia restaurativa. Procesos de apoyo al desistimiento. Practicas prometedoras, surgida gracias al estudio de los relatos de 90 ex infractores juveniles y adultos que habían participado en mediación o conferencia víctima-delincuente en Austria, Bélgica e Irlanda del Norte. El objetivo de la investigación estaba dirigido a descubrir los factores y dinámicas que contribuyen para que 
las personas que participan de los programas de justicia restaurativa desistan de volver a delinquir (Hofinger, Lauwaert y Marsh, 2015).

En demasiadas ocasiones, el procedimiento judicial tradicional, desatiende a todas las personas participantes del delito; a la víctima como primera afectada, por supuesto, la cual no se siente escuchada, reparada o ni siquiera atendida dentro de este proceso formal. También a la persona que infringe la Ley y a la que únicamente se le aplican consecuencias a su conducta delictiva, como manera de resolver tal hecho. Además, el entorno social en el que el delito ha sido cometido no tiene papel ninguno aquí.

La posibilidad de diálogo y de encontrar fórmulas alternativas y compartidas de gestión de esta conducta delictiva deja espacio para que entren en juego estos otros procesos personales y sociales transformativos, responsabilizadores y reparadores, los cuales son capaces de cambiar la experiencia de participar en la gestión del delito.

\section{Justicia restaurativa en España}

En 2015 en nuestro país, se promulgan dos Leyes llamadas a ampliar la presencia de la Justicia restaurativa en el sistema penal español: la LO 1/2015, de 30 de marzo, por la cual se reforma el Código Penal; y la Ley 4/2015, de 27 de abril, del Estatuto de la víctima del delito.

El artículo de nuestro ordenamiento jurídico penal de personas adultas que abre puertas al uso de la Justicia restaurativa en España se recoge en el artículo 21.5 del Código Penal, donde se indican las circunstancias atenuantes: "La de haber procedido el culpable a reparar el daño ocasionado a la víctima, o disminuir sus efectos, en cualquier momento del procedimiento y con anterioridad a la celebración del acto del juicio oral». En base a dicho artículo se han sustentado las distintas experiencias de mediación penal llevadas a cabo en España en los últimos 30 años.

La justificación jurídica de aplicar prácticas restaurativas en los escenarios propios de la Administración Penitenciaria —el de la privación de libertad y el de las penas y medidas comunitarias-, se sustenta, en el primer caso en el artículo 90.2 del Código Penal que contempla la posibilidad de que las personas condenadas participen en programas de reparación a las víctimas de forma favorable y efectiva como requisito para la obtención de la libertad condicional adelantada. En el segundo caso, en el artículo 49 CP, el cual refiere la posibilidad de aplicar como condena a delitos leves y menos graves la pena de TBC, y en el artículo 84.1 CP, que recoge la posibilidad de suspender la ejecución de la pena impuesta condicionado al cumplimiento del acuerdo alcanzado por las partes, en virtud de la mediación. 
En la reforma del Código Penal citada se modificó el artículo 84.1, donde se hace referencia expresa y por primera vez a la práctica de la mediación en personas adultas, como medida que puede suspender la pena. También se abren las puertas al principio de oportunidad para los delitos leves en los que no concurra interés público.

Pero también cabe destacar la Ley 4/2015, de 27 de abril, del Estatuto de la víctima del delito, donde se hace referencia por primera vez en España al término de Justicia Restaurativa en un texto normativo. Indica en su artículo $3^{\circ}$ que toda víctima tiene derecho a la protección, información, apoyo, asistencia y atención, así como a la participación activa en el proceso penal y a recibir un trato respetuoso, profesional, individualizado y no discriminatorio desde su primer contacto con las autoridades o funcionarios, durante la actuación de los servicios de asistencia y apoyo a las víctimas y de justicia restaurativa, a lo largo de todo el proceso penal y por un período de tiempo adecuado después de su conclusión, con independencia de que se conozca o no la identidad del infractor y del resultado del proceso.

Las víctimas, conforme a su Estatuto y según lo indicado en el artículo 15, podrán acceder a servicios de Justicia restaurativa, en los términos que reglamentariamente se determinen, con la finalidad de obtener una adecuada reparación material y moral de los perjuicios derivados del delito, cuando se cumplan los siguientes requisitos:

a) El infractor haya reconocido los hechos esenciales de los que deriva su responsabilidad;

b) La víctima haya prestado su consentimiento, después de haber recibido información exhaustiva e imparcial sobre su contenido, sus posibles resultados y los procedimientos existentes para hacer efectivo su cumplimiento;

c) El infractor haya prestado su consentimiento;

d) El procedimiento de mediación no entrañe un riesgo para la seguridad de la víctima, ni exista el peligro de que su desarrollo pueda causar nuevos perjuicios materiales o morales para la víctima; y

e) No esté prohibida por la ley para el delito cometido.

Es igualmente necesario que se realice una labor de divulgación, formación, e impulso ante Fiscalía, Jueces y Tribunales de todo el ámbito estatal, para que el desarrollo de cuantas premisas recoge el Estatuto de la Victima respecto a los servicios de Justicia restaurativa sea adecuadamente cumplido.

Desarrollar una mediación penal entre víctima y persona penada en este momento procesal resulta útil tanto para posibilitar la reparación de la víctima a todos los niveles una vez obtenida la respuesta del sistema 
de justicia penal, como para determinar el modo en que cada penado/a va a cumplir su condena.

\section{Justicia restaurativa en instituciones penitenciarias}

Para Penas y Medidas Alternativas, la Secretaría General de Instituciones Penitenciarias firmó en 2016 y 2017 convenios de colaboración con la Asociación Andaluza de Mediación (AMEDI) y la Federación Española de Justicia Restaurativa, que engloba a varias entidades, entre ellas CONCAES (Confraternidad Carcelaria de España), AMEDI, Soluciona y AMPC (Asociación de Mediación y Pacificación).

El objetivo de estos convenios fue la puesta en marcha, en 2017 y 2018 , de talleres piloto de justicia restaurativa para intervenir con personas condenadas a trabajos en beneficio de la comunidad. El convenio abarca, no obstante, otras líneas de trabajo, como por ejemplo el desarrollo de programas de justicia restaurativa como requisito para la libertad condicional adelantada o la suspensión de condena.

Estos talleres iban dirigidos a personas con TBC de hasta 90 jornadas incluyéndose penados de diversas etiologías delictivas, aunque se consideran como criterios de exclusión aquellos condenados por violencia de género o violencia sexual y personas con problemas de trastorno mental o drogodependencia que les impidan una participación adecuada en el taller.

En el ámbito del medio abierto se ha impulsado el desarrollo de estos talleres para internos en tercer grado desde el año 2019. Aunque ya existían iniciativas anteriores (como los talleres realizados por la entidad AMEE en el CIS de Navalcarnero tras convenio firmado en 2016), fue el año pasado cuando se centralizó la implementación de talleres de justicia restaurativa a través de la subvención de IRPF.

En el año 2019 se ha llevado a cabo como iniciativa piloto un taller mixto en el Centro Penitenciario de Valladolid. En este taller participan internos en segundo grado, tercer grado, libertad condicional y medidas alternativas. Los objetivos y metodologías del taller son las mismas expresadas anteriormente. La novedad de este taller es que se ha puesto en marcha un protocolo de coordinación entre el Centro Penitenciario, el Juez de Vigilancia Penitenciaria y la entidad de justicia restaurativa (asociación AMEE) para intentar llevar a cabo encuentros directos víctima-victimario.

Durante el año 2019 se impulsó este tipo de talleres tanto para personas condenadas a una medida alternativa como para personas privadas de libertad, poniendo el énfasis en la posibilidad de realizar un Encuentro Restaurativo entre la persona penada y la víctima directa de su delito.

Como evolución de estos talleres y para dar una respuesta a esta iniciativa surge esta línea de tratamiento penitenciario a través de los 
valores y métodos restaurativos, con personas clasificadas en segundo grado de tratamiento y a través de grupos mixtos, con personas clasificadas tanto en tercer grado como en situación de libertad condicional.

Para este nuevo modelo de Justicia Penal, la Administración Penitenciaria cuenta con el conjunto del victimario, tanto de personas condenadas a penas privativas de libertad como a Penas y Medidas Alternativas, pero necesita en esta ecuación el acceso a las víctimas y la participación de la Comunidad.

Es un proceso, por tanto, que requiere la movilización de todas las Instituciones implicadas en el logro del objetivo común, a través del desarrollo de Convenios y de la protocolarización, desde el más absoluto respeto y voluntariedad, del acceso y relación con las víctimas.

El modelo de Justicia penal inicia, pues, una transformación para ajustarse a una nueva sociedad, con valores, estrategias y metodología también nuevas, donde la cooperación interinstitucional es necesaria con el fin de conseguir un bien común para el conjunto de los ciudadanos y para el que estas mismas Instituciones deben mostrar una actitud de entendimiento y colaboración.

Para impulsar estos procesos restaurativos se necesita contar necesariamente con la colaboración del Consejo General de Poder Judicial, la Fiscalía General del Estado, y el Ministerio de Justicia, creando un protocolo de contacto con la víctima para que forme parte del proceso si voluntariamente aceptara.

\section{Cambio de paradigma/proyecto global}

Todas las definiciones coinciden en señalar los tres pilares sobre los que se sustenta la justicia restaurativa, que son la responsabilización de la persona infractora, la reparación del daño y la participación de la comunidad en el proceso restaurativo.

La Justicia restaurativa es un modelo alternativo de Justicia cuyo objetivo es reparar el daño causado a la víctima. Se trata de un proceso en el que interviene siempre una tercera persona ajena al conflicto que media entre víctima y la persona denunciada para que esta última ayude a la primera a superar la situación que ella misma ha originado.

La Secretaría General ha asumido la Justicia restaurativa como un gran Proyecto Global en todas las áreas de competencia que le son propias, es decir, tanto en la pena privativa de libertad, en cualquiera de sus grados de cumplimiento, incluyendo la Libertad Condicional como en las Penas y Medias Comunitarias, tal que el cumplimiento de los Trabajos en Beneficio de la Comunidad, como en las suspensiones de condena. 
Se plantea como un objetivo a conseguir que en el transcurso de 2021 y en el 2022, esté implementada en todos los Centros Penitenciarios, Centros de Inserción Social y Servicios de Gestión de Penas y Medidas Alternativas.

Para ello ya están publicados los materiales (Taller de Diálogos Restaurativos y Programa de Encuentros Restaurativos Penitenciarios) que se van a utilizar de manera uniforme y homologada en todo el territorio, de tal forma que se trabaje con la misma metodología, los mismos contenidos y las mismas dinámicas en todos los Centros competencia de la Secretaría General de Instituciones Penitenciarias.

Al mismo tiempo, se están promoviendo convenios tanto con Entidades del tercer sector, Asociaciones, Federaciones de Justicia Restaurativa para el desarrollo de los Talleres y Programas, de tal manera que la ejecución de los mismos esté a cargo de profesionales formados y objetivos no pertenecientes a la Institución Penitenciaria.

También se están gestionando convenios con otras Instituciones tales como el Consejo General del Poder Judicial, el Ministerio de Justicia, las Oficinas de Atención a la Víctima de las Comunidades Autónomas, Universidades, Fiscalía General del Estado, etc.

\section{Taller de diálogos restaurativos}

El Taller Diálogos Restaurativos: Responsabilización y Reparación del Daño cumple con el objetivo reeducativo y reparador que ha de caracterizar los TBC y las penas privativas de libertad, favoreciendo la ruptura del itinerario delincuencial, y así, evitar la reincidencia.

Más allá de las aportaciones penológicas de la presente propuesta, los Diálogos restaurativos, ofrecen una valiosísima oportunidad a las personas penadas para entender el impacto de su delito, más allá de sí mismas y su entorno próximo; conectar con la vivencia de la persona que ha sufrido como víctima las consecuencias del delito, y sentir la necesidad de buscar fórmulas de reparación dentro del contexto social en el que el delito ha sido cometido.

Como planteamiento necesario entonces, en la elaboración de este Taller se ha tenido en cuenta un elemento muy importante y que entendemos también esencial desde los planteamientos restaurativos y su modo de entender el delito: el rol de la víctima en el proceso de afrontamiento del delito y sus efectos. Desde esta perspectiva, los Diálogos restaurativos, además de poner el acento en la persona penada, para que del cumplimiento de la pena pueda obtener un beneficio personal que le ayude en su vida futura, tenemos también en cuenta a la víctima. Esta, a la vista del trabajo de empatía y responsabilización realizado con la 
persona penada, también tiene la oportunidad de obtener un beneficio personal por su participación en esta práctica restaurativa.

La participación en este Taller, así como en cualquier práctica restaurativa, tal como la mediación u otras, sirve como vehículo para la reintegración de las personas penadas por la comisión de un delito dentro de su entorno social y como oportunidad de huir del círculo vicioso de la reincidencia. En demasiadas ocasiones, el procedimiento judicial desatiende a todas las personas participantes del delito; a la víctima como primera afectada, por supuesto, la cual no se siente escuchada, reparada o ni tan siquiera atendida dentro de este proceso formal. También a la persona que infringe la Ley y a la que únicamente se le aplican consecuencias a su conducta delictiva, como manera de resolver tal hecho. Además, el entorno social en el que el delito ha sido cometido no tiene papel ninguno aquí. La posibilidad de diálogo y de encontrar fórmulas alternativas y compartidas de gestión de esta conducta delictiva da espacio para que entren en juego estos otros procesos personales y sociales transformativos, responsabilizadores y reparadores, los cuales son capaces de cambiar la experiencia de participar en la gestión del delito.

En este sentido, el Taller Diálogos Restaurativos: Responsabilización y Reparación del Daño, como se desarrollará con detenimiento en este texto, añade al trabajo grupal característico de los Diálogos restaurativos la posibilidad de participar en un proceso de mediación penal para aquellas personas que deseen una práctica restaurativa más directa e íntima, siempre desde la participación libre y voluntaria de las personas implicadas.

\section{Encuentros Restaurativos Penitenciarios}

Los Encuentros Restaurativos Penitenciarios van dirigidos tanto a personas penadas que cumplen una medida comunitaria como a personas privadas de libertad, incluida la libertad condicional. Se puede realizar siempre que las partes estén preparadas y voluntariamente accedan a ello como se expone más adelante en este documento. En concreto, en los encuentros restaurativos entre la persona penada y la víctima, se pueden diferenciar tres alternativas:

- Encuentro restaurativo con víctima directa, es decir, toda persona física que haya sufrido un daño o perjuicio sobre su propia persona o patrimonio.

- Encuentro restaurativo con víctima indirecta, es decir, familiares o personas allegadas de las víctimas directas.

- Encuentro restaurativo con víctima no vinculada, es decir, personas afectadas por la lesión de bienes jurídicos similares a aquellos dañados por el delito cometido. 
Encuentros Restaurativos Penitenciarios incluye la siguiente metodología:

- Sesiones individuales y/o grupales con víctima y persona penada anteriores al posible Encuentro Restaurativo.

- Encuentro Restaurativo.

- Sesiones individuales y/o grupales con víctima y persona penada posteriores al Encuentro Restaurativo.

Es importante señalar que en este documento sólo se presenta el contenido de las sesiones a realizar con la persona penada y la víctima, en caso de realizarse un Encuentro Restaurativo Penitenciario. Sin embargo, respecto al protocolo a seguir para poder acceder a la víctima, el consentimiento informado y otros aspectos procedimentales se atenderá a las instrucciones dadas por la Secretaría General de Instituciones Penitenciarias.

\section{Implementación}

a) Medidas Comunitarias

- 2017: Sevilla y Málaga: 38 participantes

- 2018: Algeciras, Huelva, Madrid, Málaga, Sevilla y Toledo372 participantes

- 2019: Algeciras, Almería, Granada, Huelva, Madrid, Málaga, Sevilla, Toledo, Valencia y Valladolid- 534 participantes

- 2020: Alicante, Andalucía, Madrid, Murcia, Toledo, Valladolid y Zaragoza- 725 participantes

- 2021: Presencia en todas las CCAA.

b) Medio Abierto

- 2019: Madrid, Málaga y Valencia: 100 participantes

- 2020: Andalucía, Madrid, Murcia, Valencia y Valladolid: 130 participantes. 


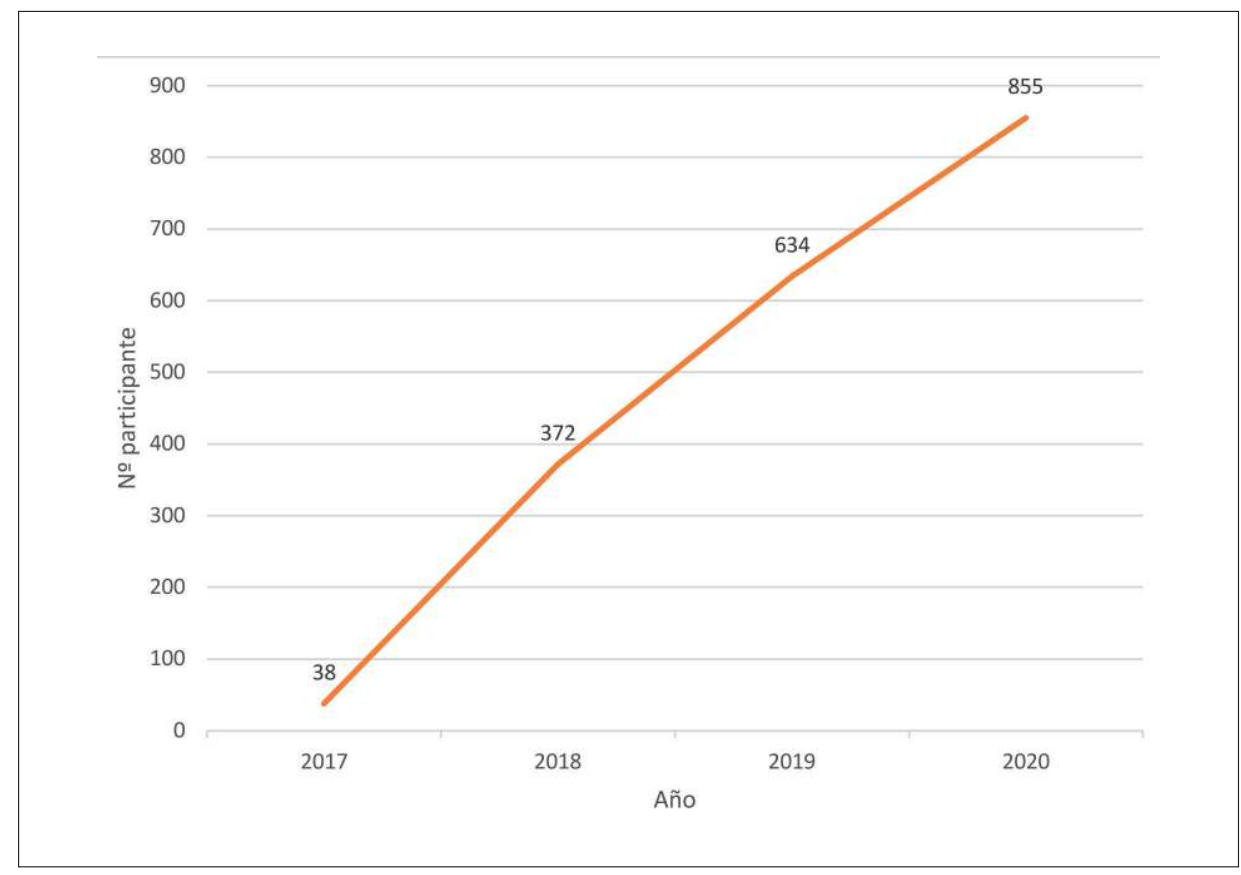

\section{Futuro de la Justicia restaurativa}

El 29 de octubre de 2020, quedó constituido un Grupo de Trabajo para la coordinación de todas las actuaciones en materia de Justicia restaurativa, con el Secretario General de Instituciones Penitenciarias, el Director General de Ejecución Penal y Reinserción Social, las Responsables de las Subdirecciones de Tratamiento y Gestión y la de Medio Abierto y Medidas Alternativas, la Coordinadora General y otros profesionales, para establecer un decálogo, una temporalización y una coordinación que permita llevar a cabo este gran Proyecto.

Las líneas a trabajar son las siguientes.

1. Los Talleres y Programas de Justicia Restaurativa desarrollados en IIPP, ya sea en los centros penitenciarios, como en los CIS, o en los SGPMA, deberán responder al Programa y Taller publicados por el Programa Editorial del Ministerio del Interior, denominados Talleres «Diálogos Restaurativos» y Programa «Encuentros Restaurativos». Al respecto, hemos de tener en consideración que tras varios años de afanado trabajo conjunto entre entidades expertas en Justicia restaurativa y trabajadores penitenciarios, se ha logrado formalizar estos documentos de trabajo, respondien- 
do a unos estándares de calidad idóneos para el fin propuesto, y avalados por la Administración Penitenciaria.

2. El contenido, metodología empleada, duración, y evaluación de estos Talleres y Encuentros Restaurativos será uniforme, de forma tal que los internos e internas y las personas condenadas a medidas alternativas puedan acceder a estos, con independencia del lugar de cumplimiento de su condena; brindándose las mismas oportunidades de intervención para nuestros administrados, y los mismos criterios y patrones de calidad requeridos.

3. Las entidades expertas en mediación son las encargadas del desarrollo de estos Talleres y Programas (no los propios profesionales penitenciarios), puesto que prima en su práctica la preparación específica de estos profesionales externos, y puede ser un inconveniente la intervención de personal penitenciario, al tener una relación especial de sujeción para con los internos/as y tener responsabilidades administrativas con las personas sometidas a medidas alternativas. La víctima será atendida en las sesiones correspondientes del taller/programa por estos mismos facilitadores, no por personal penitenciario. Se garantiza así la imparcialidad, la cercanía, y la salvaguarda de las víctimas.

4. Analizadas las diferentes vías de acceso a los datos de las víctimas, teniendo la experiencia de diversos enfoques y soluciones, en principio se debe atender al soporte que pueden ofrecer las Oficinas de Atención a Víctimas, dependientes de las CCAA, mediante contactos coordinados con las Administraciones responsables de sus cometidos y funciones.

5. Respecto a los participantes (internos/sometidos a medidas alternativas) en los Talleres y Programas, serán de elección por la Administración Penitenciaria. Así, los equipos técnicos y Juntas de Tratamiento correspondientes realizarán una primera selección de participantes, que después será también contrastada por la entidad facilitadora en una primera sesión individual, viendo la conveniencia o no de la selección realizada. En ningún caso la participación en estos Talleres/programas llevará aparejado automáticamente el logro de beneficios penitenciarios.

6. En el desarrollo de actuaciones de JR en el régimen ordinario de tratamiento, en los supuestos de realización del Módulo de Justicia Restaurativa "Encuentros Restaurativos» unido a otro programa de intervención, por ejemplo, tras el programa de igualdad de trato y no discriminación y frente a delitos de odio (Programa DIVERSIDAD) o para delincuentes del ámbito socioeconómico (Programa PIDECO), no se evaluarán con buen aprovechamiento los mismos si no se completa su desarrollo como con este módulo restaurativo. Módulo que en el régimen ordinario se establece como obligatorio. 
7. Se estima muy necesario establecer Convenios de Colaboración con diferentes Administraciones Autonómicas y sus respectivas Direcciones Generales competentes en materia de Victimas, para mejor trabajo y coordinación con las Oficinas y Servicios de Atención a Víctimas.

8. Las entidades colaboradoras deberán firmar un convenio de colaboración con IIPP para el cometido que se les encomienda en este campo, cuyo modelo es único y común para todas sus intervenciones. El Convenio no implica en ningún caso compromisos de gastos para la Administración Penitenciaria. Los costes que generan estas colaboraciones serán sufragados a través de determinadas Subvenciones, partidas presupuestarias incluidas en los Presupuestos Generales del estado (483), o a través de otras vías de financiación. Al respecto es importante la implicación de las diferentes CCAA.

9. Todas las iniciativas de intervención en Justicia restaurativa que surjan en los centros o CIS, deben ser puestas en conocimiento de los miembros del Grupo de trabajo constituido, para mejor coordinación y seguimiento.

\section{Bibliografía}

Becoña, E. (2006). Resiliencia: Definición, características y utilidad del concepto. Psicopatología y Psicología Clínica, 11(3), 125-146.

BRown, S. (2005). Understanding youth and crime: Listening to youth? United Kingdom: McGraw-Hill Education.

CAREY, M. (1998). A voluntary organization in the prison system ... Inside Out Trust. En Dhami, M., Mantle, G. y Fox, D. (2009). Restorative justice in prisons. Contemporary Justice Review. 12(4), 433-448.

CARICH, M. S., Y CALDER, M. C. (2003). Contemporary treatment of adult male sex offenders. Reino Unido: Crown House Publishing Limited.

Dhami, M, Greg, M y Darrell, F. (2009). Restorative justice in prisons. Contemporary Justice Review. 12 (4), 433-448.

Fernández, Y., Marshall, W., Lightbody, S., y O'Sullivan, C. (1999). The Child Molester Empathy Measure: Description and examination of its reliability and validity. Sexual Abuse: A Journal of Research and Treatment, 11(1), 17-31.

Forés, A. y Grané, J. (2008). La resiliencia. Crecer desde la adversidad. Barcelona: Plataforma.

Gómez, R. (2009). Violencia en los Comportamientos Humanos. Valoración de la Peligrosidad en Presos Reincidentes. Anuario de Psicología Jurídica, 19, 43-60. 
Guardiola Lago, M. J. y TAmarit Sumalla, J. (2013). La justicia restaurativa y los paradigmas alternativos de justicia. Barcelona: UOC.

Hofinger, V, LAUWAERT, K y MARsh, B. (2015). Guía para el desarrollo de la justicia restaurativa y procesos de apoyo de desistimiento. Leuven: European Forum for Restorative Justice.

Igartua, I., Olalde, A. y Varona, G. (2012). Diccionario breve de justicia restaurativa: una invitación interdisciplinar e introductoria a sus conceptos clave. Saarbrücken, Alemania: Editorial Académica Española.

Johnstone, G y KlaAssen, E. (2015). Construyendo Puentes. Diálogos restaurativos entre víctimas y delincuentes. Una Guía para el establecimiento y ejecución del Programa Construyendo Puentes. UE: Buildingbridges.

Liebmann, M. (2010). Restorative Justice in prisons- An international perspective. Brazil: United Nations Crime Congress. Recuperado de: https://www.foresee.hu/uploads/media/MarianLiebmann_text.pdf.

Marshall, T. (1999). Restorative Justice. An Overview, London: Home Office.

Nogueras, A y Gimeno, R. (2012). De la «Mediación y la Reparación a la Víctima» a la "Prevención». Revista de Educación Social, 15, 1-15.

Olalde Altarejos, A. (2006). Justicia Restaurativa y mediación en el ámbito penal. Apuntes Máster de mediación familiar y social de la Universidad de Murcia. Disponible en http://servicios.educarm.es/templates/ portal/ficheros/websDinamicas/102/APUNTES\%20ALBERTO\%20 OLALDE $\% 5 B 1 \% 5 D \% 5 B 1 \% 5 D \_1 . p d f$. Recuperado el 11 de febrero de 2020.

Olalde Altarejos, A.J. (2015). Estudio multidimensional de algunas prácticas de Justicia Restaurativa en el País Vasco con Lentes de Trabajo Social (2007-2012). (Tesis doctoral). Universidad de Murcia.

Ollero Peran, J. (2013). Menos prisión y más Justicia restaurativa: estableciendo las prioridades del debate. Revista de Criminología y Justicia, 1-18.

OrTiz GonzÁlez, A.L. (2008). Mediación penal y penitenciaria: propuestas para el futuro. Familia: Revista de ciencias y orientación familiar, 36, $11-24$.

Palma, L. (2007). La Mediación como Proceso Restaurativo en el Sistema Penal (Tesis doctoral). Universidad de Sevilla.

Pascual, E. (coord.) (2013). Los ojos del otro. Encuentros restaurativos entre víctimas y ex miembros de ETA. Madrid: Sal Terrae.

Peters, T. y Robert, L. (2003). Cómo la restauración puede saltar los muros de la cárcel. Una discusión sobre el proyecto Detención dirigida a la Restauración. Revista Eguzkilore, 17, 161-185. 
Ríos Martín, J.C., Bibiano Guillén, A., Etxebarria Zarrabeitia, X., Lozano Espina, F., Pascual Rodríguez, E. y Segovia Bernabé, J.L. (2012). Mediación penal, penitenciaria y encuentros restaurativos. Experiencias para reducir el sufrimiento en el sistema penal. $3^{\mathrm{a}}$ ed. Madrid: COLEX.

\section{Documentos}

Comité de Ministros del Consejo de Europa referente a la Justicia Restaurativa en asuntos penales (1999). Recomendación No. R (99) 19. https://www.dvjj.de/sites/default/files/medien/imce/documente/themenschwerpunkte/Internationale/ER_03_Rec\%20\%2899\%2919\%20 mediation\%20in\%20penal\%20matters.pdf.

Comité de Ministros del Consejo de Europa referente a la Justicia Restaurativa en asuntos penales (2018). Recomendación 2018. http:// www.euforumrj.org/news/coe-recommendation-rj-adopted/.

CONCAES (2015). Manual Construyendo Puentes. Madrid: Confraternidad Carcelaria Española.

Intervención en Justicia restaurativa: Encuentros Restaurativos Penitenciarios. Ministerio del Interior, 2021. http://www.interior.gob.es/ documents/642317/1201664/Intervenci\%C3\%B3n_en_justicia_restaurativa_DP-24_web_126200539.pdf/323bebe7-cbfa-45d8-9cef840ce824d693\#: :text=Los\%20Encuentros\%20Restaurativos\%20 Penitenciarios $\% 2$ C $\% 20$ constan,se $\% 20$ celebrar $\%$ C3\%A1\%20el\%20 Encuentro\%20Restaurativo.

Naciones Unidas (2006). Manual sobre Programas de Justicia Restaurativa. Serie de manuales sobre justicia penal. Nueva York: Oficina de las Naciones Unidas contra la Droga y el Delito (UNODC).

Taller de Diálogos Restaurativos: Responsabilización y reparación del daño. Ministerio del Interior, 2021. http://www.interior.gob.es/documents/642317/1201664/Taller_de_Di\%C3\%A1logos_Restaurativos_ DP-23_web_126200630.pdf/af4b6ea9-c552-4acb-a67a-3172ac9902f7. 